\title{
DEVELOPMENT AND IN VIVO EVALUATION OF MUCOADHESIVE MICROSPHERES USING PIRENZEPINE
}

\section{KANTEEPAN P, BHIKSHAPATHI DVRN*}

Department of Pharmacy, Mewar University, Chittorgarh, Rajasthan, India. Email: dbpathi71@gmail.com

Received: 09 March 2018, Revised and Accepted: 12 April 2018

\section{ABSTRACT}

Objective: The current investigation objective was to fabricate gastroretentive mucoadhesive microspheres of pirenzepine and to investigate the pharmacokinetic parameters of optimized formulation in comparison with a marketed product.

Methods: Pirenzepine mucoadhesive microspheres prepared using ionotropic gelation technique. Evaluation parameters and characterization such as Fourier transform infrared (FTIR) and scanning electron microscopy were performed. In vivo bioavailability studies were conducted in rabbits. The technique used was found to be handling easy, inexpensive, and reproducible process.

Results: Among the total 14 formulations, M13 formulation was optimized and showed free flowing with good packability. FTIR studies investigated incompatibility were not observed between drug and excipients. The optimized formulation (M13) showed best cumulative percentage drug release of pirenzepine up to $99.07 \pm 0.17 \%$ within $12 \mathrm{~h}$ whereas marketed product displayed the drug release of $95.23 \pm 0.21 \%$ within $1 \mathrm{~h}$. The release mechanism from microspheres followed the zero-order and Korsmeyer-Peppas model $\left(\mathrm{R}^{2}=0.951\right.$ and 0.994$)$, respectively. Optimized formulation (M13) was stable at $40^{\circ} \mathrm{C} \pm 2^{\circ} \mathrm{C} / 75 \% \mathrm{RH} \pm 5 \% \mathrm{RH}$ for 6 months. Form in vivo studies, the optimized formulation bioavailability was much higher than the marketed product.

Conclusion: Microspheres would be a promising drug delivery system could play a potentially significant role in pharmaceutical drug delivery in a controlled manner for an extended period of time for effective management of gastritis.

Keywords: Pirenzepine, Mucoadhesive microspheres, Gastritis, In vivo Bioavailability studies.

(C) 2018 The Authors. Published by Innovare Academic Sciences Pvt Ltd. This is an open access article under the CC BY license (http://creativecommons. org/licenses/by/4. 0/) DOI: http://dx.doi.org/10.22159/ajpcr.2018.v11i7.25777

\section{INTRODUCTION}

Gastritis is a chronic inflammatory disease of the stomach mucosa. Nowadays, the occurrence and frequency of gastritis are increasing, especially in developed countries [1]. Conventional drug delivery systems (DDS) cannot achieve prolongation of plasma drug concentration and effective bioavailability this is because of gastric emptying, $\mathrm{pH}$ of the stomach, etc., which can be overcome by developing gastric retention and long-acting release drug products [2]. There is need to develop new drugs and novel formulations as an alternative to existing formulations. Oral controlled DDS continues to be the most accepted and popular one among all the delivery systems [3]. To achieve this goal a variety of system has been developed including mucoadhesive and hydrogels among these the mucoadhesive DDS offers several advantages for those drugs associated with poor bioavailability and narrow absorption window in the gastrointestinal tract (GIT) upper part [4]. Mucoadhesive system had selected in the present research work. From the scientific and patent literature and due to advancements in controlled DDS, it is marked that if gastroretentive dosage forms retain in GIT for a time, then the drug is released slowly over a long period of time [5]. Mucoadhesive microspheres have advantages such as efficient absorption, enhanced bioavailability of drugs, maximum utilization of drug, and a much more intimate contact with mucous membrane [6]. It clearly indicated that these dosage forms can control the drug release at gastric region without getting cleared from the GIT; hence, it avoids the fluctuations and reducing the requirement of several administrations [7].

Pirenzepine, a selective antimuscarinic agent, is being investigated for clinical efficacy in the treatment of gastritis and ulcer. In contrast to the traditional antimuscarinic agents, pirenzepine shows selectivity for muscarinic receptors. Pirenzepine associated with low bioavailability (25\%), hence, is rapidly metabolized into its inactive metabolite within liver and colonic environment so the efficacy would be reduced and requires multiple dosing for maintaining therapeutic effect throughout the day. One approach to avoid this problem would be control the drug release, hence, increases the bioavailability at in situ level [8].

In oral controlled drug delivery, one of the finest microparticulate systems is microspheres. Microspheres can be defined as solid, spherical particles size ranging from 1 to $1000 \mu \mathrm{m}$. The drug may be dispersed either in solution/microcrystalline form [9]. Microspheres offer advantages such as reducing dosing frequency and fluctuations and maintaining drug within the therapeutic range. Several varieties of biodegradable polymers were used for the preparation of microspheres. Polymeric DDS displays several advantages over the conventional dosage forms, and it includes enhanced efficacy, patient compliance, reduced toxicity, and to control the encapsulated drug release. Sodium alginate is an anionic natural polysaccharide, prepared by a mixture of D-mannuronic acid and L-glucuronic acid [10]. Sodium alginate is extensively used as a carrier for drug delivery due to its biocompatibility and low toxicity. The widely used method for pirenzepine microspheres preparation is an ionotropic gelation method [11]. This technique offers several advantages such as simple method of preparation no need to use organic solvent, and, also easier to control. Sodium alginate could form a gel in the presence of multivalent cations such as $\mathrm{Ca} 2+$, $\mathrm{Zn} 2+, \mathrm{Ba} 2+$, and $\mathrm{Al} 3+$ by ionic cross-linking to form microspheres; it has been widely used in sustained drug release. Hence, in this study calcium chloride is selected as a cross-linking agent and because of its nontoxic and biocompatibility. Chitosan and sodium carboxymethylcellulose (CMC) are used as mucoadhesive agents [12].

In our present research work, the main aim of the study was to develop and evaluate gastroretentive mucoadhesive microspheres 
of pirenzepine and to investigate the pharmacokinetic parameters of optimized formulation in comparison with a marketed product.

\section{MATERIALS AND METHODS}

\section{Materials}

Pirenzepine was procured as a sample of a gift from Splendid laboratories, Pune, India. Sodium alginate was used as polymer obtained from Pruthvi Chemicals, Mumbai. Calcium chloride was purchased from SD fine chemicals Mumbai, India. Chitosan and sodium CMC were purchased from Rubicon Labs, Mumbai, India. All other chemicals used were of analytical grade.

\section{Formulation of pirenzepine mucoadhesive microspheres}

Chitosan and sodium CMC as a mucoadhesive agent, sodium alginate as a microsphere core forming agent, and calcium chloride as cross-linking agent were used for the formulation and preparation of pirenzepine microsphere.

\section{Preparation of mucoadhesive microspheres}

Pirenzepine mucoadhesive microspheres were prepared by ionotropic gelation method using sodium alginate in combination with mucoadhesive polymers, namely chitosan and sodium CMC as mentioned in Table 1. Initially, sodium alginate solution was prepared by solubilizing the weighed quantity of it, chitosan and sodium CMC in deionized water using gentle heat, being stirred magnetically. In between the stirring time, $100 \mathrm{mg}$ of pirenzepine was added to $100 \mathrm{ml}$ of each percentage solution to form homogeneous dispersions at $500 \mathrm{rpm}$, maintained room temperature. The mixtures were sonicated for $30 \mathrm{~min}$ to eliminate air bubbles that may have been formed during the stirring process. The above dispersion $(100 \mathrm{ml})$ was extruded dropwise through 20G needle fitted with a $10 \mathrm{ml}$ syringe into $100 \mathrm{ml}$ of $7 \% \mathrm{w} / \mathrm{v}$ and $10 \% \mathrm{w} / \mathrm{v}$ of calcium chloride solution, being stirred at $500 \mathrm{rpm}$ for $10 \mathrm{~min}$. Later, the microspheres were collected by decantation and washed repeatedly with deionized water. The pirenzepine microspheres could dry at $60^{\circ} \mathrm{C}$ for $2 \mathrm{~h}$ in a hot-air oven [13].

\section{Evaluation parameters of pirenzepine mucoadhesive microspheres} Micromeritic properties

Micromeritic properties were used for the assessment of flowability and characterization of microspheres such as angle of repose, bulk density, tapped density, Carr's index, and particle size.

\section{Swelling index}

The swelling index was determined by suspending the weighed quantities of microspheres in $0.1 \mathrm{~N} \mathrm{HCl}$ with $\mathrm{pH} 1.2$ and allowed to swell for the specified period. The excess surface adhered liquid drops of swollen microspheres were removed using blotting paper and then weighed it with the help of a microbalance. The swollen microspheres were dried in an oven at $60^{\circ} \mathrm{C}$ for $5 \mathrm{~h}$ or until showed the constant weight [14]. The swelling index was determined using the initial weight of microspheres with respect to the weight of microspheres after drying (final weight) as per the formula below mentioned.

Swelling index $=$ (Mass of swollen microspheres-Mass of dry microspheres/mass of dried microspheres) $\times 100$.

\section{Percentage yield}

The prepared microspheres were collected, dried and weighed. The percentage yield was calculated by taking the weight of dried microspheres divided by the total weight of drug and all excipients used in the microspheres preparation. It was determined using the following formula:

percentage yield $=[$ Total weight of microspheres/Total weight of drug and polymer $] \times 100$

\section{Entrapment efficiency}

The weighed quantity of prepared pirenzepine microspheres was transferred in a mortar and crushed. The crushed microspheres were dissolved in $50 \mathrm{ml}$ of methanol then transferred into $100 \mathrm{ml}$ conical flask and made the volume up to the mark using methanol. The above solution was agitated to dissolve the drug, all excipients and to extract the drug. The solution was filtered through a membrane filter $(0.45 \mu \mathrm{m})$ to separate shell fragments. The solution was diluted suitably, and the absorbance was estimated at the $\lambda_{\text {max }}$ of $280 \mathrm{~nm}$ by using a double beam spectrophotometer (Shimadzu, UV-1800) [15]. The amount of drug entrapped was determined using the following equation.

Percentage drug entrapment=Calculated drug concentration/ Theoretical drug concentration $\times 100$

\section{Ex vivo mucoadhesion study}

The microspheres mucoadhesive property was assessed by ex vivo mucoadhesion method using a chicken small intestinal tissue. The mucosal membrane was excised and washed with saline. $5 \mathrm{~cm}$ of jejunum portion was separated and averted with a glass rod. About 100 microspheres were spread uniformly on the tissue specimen. Then, both ends of the segment were tied using a thread. The tissue specimen was suspended in a $50 \mathrm{ml}$ tube containing $40 \mathrm{ml}$ of saline at $37^{\circ} \mathrm{C}$ and stirred horizontally. The tissue specimen was removed from the medium at specified time periods such as $1,2,3,4,5,6,7$, and $8 \mathrm{~h}$, then immediately immersed into a tube containing $40 \mathrm{ml}$ of fresh saline and unbound microspheres were counted [16]. The adhering percent was calculated using the formula shown below.

Mucoadhesion=(No. of microspheres adhered/No. of microspheres applied) $\times 100$

Table 1: Formulation trials for pirenzepine mucoadhesive microspheres

\begin{tabular}{|c|c|c|c|c|}
\hline Formulation code & Pirenzepine (mg) & Sodium alginate $(\%)$ & Sodium CMC (mg) & Calcium chloride $(\%)$ \\
\hline M1 & 50 & 1 & 100 & 7 \\
\hline M2 & 50 & 1.2 & 150 & 7 \\
\hline M3 & 50 & 1.4 & 200 & 7 \\
\hline M4 & 50 & 1.6 & 250 & 7 \\
\hline M5 & 50 & 1.8 & 300 & 7 \\
\hline M6 & 50 & 2 & 350 & 7 \\
\hline M7 & 50 & 2.2 & 400 & 7 \\
\hline M8 & 50 & 1 & 10 & 10 \\
\hline M9 & 50 & 1.2 & 15 & 10 \\
\hline M10 & 50 & 1.4 & 20 & 10 \\
\hline M11 & 50 & 1.6 & 25 & 10 \\
\hline M12 & 50 & 1.8 & 30 & 10 \\
\hline M13 & 50 & 2 & 35 & 10 \\
\hline M14 & 50 & 2.2 & 40 & 10 \\
\hline
\end{tabular}

CMC: Carboxymethyl cellulose 
In vitro drug release studies

The in vitro drug release from prepared mucoadhesive microspheres was studied using USP dissolution apparatus II. Accurately, weighed the quantity of microspheres equivalent to $100 \mathrm{mg}$ of drug was transferred into $900 \mathrm{ml}$ of $0.1 \mathrm{~N} \mathrm{HCl}(\mathrm{pH} 1.2)$ medium maintained at $37 \pm 0.5^{\circ} \mathrm{C}$ and stirring at $100 \mathrm{rpm}$. Aliquots of samples were withdrawn at specified time intervals, filtered and diluted with similar medium finally assayed at $280 \mathrm{~nm}$ using a UV-Visible spectrophotometer. The samples were withdrawn and replaced with same dissolution medium at predetermined time intervals [17]. All the samples were analyzed in triplicate.

Analysis of in vitro drug release kinetics and mechanism

The in vitro release data from optimized microspheres formulation containing pirenzepine were determined kinetically using different mathematical models such as zero-order, first-order, Higuchi, and Korsmeyer-Peppas model.
Drug-excipient compatibility studies

Fourier transform infrared spectroscopy (FTIR)

The spectral analysis can be used to identify the functional groups in the pure drug and drug-excipient compatibility. Pure pirenzepine FTIR spectra and optimized formulation were recorded using FTIR (SHIMADZU). A weighed quantity of $\mathrm{KBr}$ and drug excipients was taken in the ratio 100:1 and mixed by mortar. The samples were made into a pellet by the application of pressure [18]. Then, the FTIR spectra were recorded in the wavelength region between 4000 and $400 / \mathrm{cm}$.

\section{Scanning electron microscopy (SEM) studies}

Microsphere surface character includes size and shape was examined with the help of SEM. The microspheres were dried completely before analysis and SEM carried out at different magnifications of $15.0 \mathrm{kv} \times 7.0 \mathrm{~mm}, 15 \mathrm{kv} \times 7.3 \mathrm{~mm}$, and $15 \mathrm{Kv} \times 6.4 \mathrm{~mm}[19]$.

Table 2: Micromeretic properties pirenzepine mucoadhesive microspheres

\begin{tabular}{|c|c|c|c|c|c|}
\hline Formulation code & Particle size $(\mu \mathrm{m})$ & Bulk density $\left(\mathrm{g} / \mathrm{cm}^{3}\right)$ & Tapped density $\left(\mathrm{g} / \mathrm{cm}^{3}\right)$ & Angle of repose & Carr's index (\%) \\
\hline M1 & $65.29 \pm 0.13$ & $0.63 \pm 0.05$ & $0.62 \pm 0.17$ & $29^{\circ} .67 \pm 0.11$ & $09.34 \pm 0.16$ \\
\hline M2 & $73.43 \pm 0.04$ & $0.65 \pm 0.23$ & $0.69 \pm 0.22$ & $30^{\circ} .54 \pm 0.23$ & $11.12 \pm 0.23$ \\
\hline M3 & $78.67 \pm 0.09$ & $0.67 \pm 0.18$ & $0.73 \pm 0.30$ & $28^{\circ} .15 \pm 0.31$ & $14.23 \pm 0.30$ \\
\hline M4 & $79.45 \pm 0.21$ & $0.69 \pm 0.33$ & $0.75 \pm 0.15$ & $22^{\circ} .91 \pm 0.17$ & $10.32 \pm 0.19$ \\
\hline M5 & $83.42 \pm 0.12$ & $0.72 \pm 0.14$ & $0.79 \pm 0.29$ & $27^{\circ} .93 \pm 0.27$ & $11.87 \pm 0.22$ \\
\hline M6 & $85.34 \pm 0.09$ & $0.75 \pm 0.26$ & $0.82 \pm 0.33$ & $25^{\circ} .54 \pm 0.32$ & $13.95 \pm 0.35$ \\
\hline M7 & $87.12 \pm 0.13$ & $0.76 \pm 0.12$ & $0.91 \pm 0.26$ & $23^{\circ} .91 \pm 0.18$ & $10.20 \pm 0.17$ \\
\hline M9 & $72.46 \pm 0.09$ & $0.68 \pm 0.24$ & $0.63 \pm 0.22$ & $27^{\circ} .91 \pm 0.15$ & $09.11 \pm 0.37$ \\
\hline M10 & $76.89 \pm 0.10$ & $0.72 \pm 0.37$ & $0.68 \pm 0.32$ & $30^{\circ} .24 \pm 0.26$ & $12.12 \pm 0.11$ \\
\hline M11 & $85.94 \pm 0.11$ & $0.74 \pm 0.21$ & $0.72 \pm 0.17$ & $27^{\circ} .93 \pm 0.11$ & $10.23 \pm 0.28$ \\
\hline M12 & $88.94 \pm 0.11$ & $0.79 \pm 0.38$ & $0.75 \pm 0.21$ & $22^{\circ} .34 \pm 0.37$ & $11.34 \pm 0.30$ \\
\hline M13 & $89.04 \pm 0.21$ & $0.58 \pm 0.25$ & $0.59 \pm 0.13$ & $19^{\circ} .54 \pm 0.26$ & $8.41 \pm 0.12$ \\
\hline M14 & $91.45 \pm 0.21$ & $0.83 \pm 0.10$ & $0.83 \pm 0.05$ & $24^{\circ} .91 \pm 0.10$ & $13.45 \pm 0.22$ \\
\hline
\end{tabular}

Table 3: Percentage yield, entrapment efficiency, swelling index, and mucoadhesiveness of pirenzepine mucoadhesive microspheres formulations

\begin{tabular}{llll}
\hline Formulation code & Percentage yield (\%) & Entrapment efficiency (\%) & Swelling index (\%) \\
\hline M1 & $75.45 \pm 0.24$ & $76.02 \pm 0.13$ & $72.11 \pm 0.31$ \\
M2 & $81.38 \pm 0.16$ & $82.03 \pm 0.28$ & $78.34 \pm 0.12$ \\
M3 & $82.97 \pm 0.32$ & $84.04 \pm 0.21$ & $82.89 \pm 0.25$ \\
M4 & $85.00 \pm 0.08$ & $86.00 \pm 0.11$ & $84.56 \pm 0.37$ \\
M5 & $87.02 \pm 0.14$ & $88.72 \pm 0.22$ & $85.23 \pm 0.18$ \\
M6 & $96.03 \pm 0.22$ & $90.03 \pm 0.16$ & $94.12 \pm 0.22$ \\
M7 & $92.01 \pm 0.31$ & $80.02 \pm 0.39$ & $84.23 \pm 0.10$ \\
M8 & $81.08 \pm 0.15$ & $82.05 \pm 0.17$ & $69.12 \pm 0.21$ \\
M9 & $85.00 \pm 0.22$ & $70.12 \pm 0.37$ \\
M10 & $83.00 \pm 0.20$ & $88.25 \pm 0.31$ & $75.22 \pm 0.23$ \\
M11 & $84.00 \pm 0.33$ & $91.26 \pm 0.11$ & $84.34 \pm 0.24$ \\
M12 & $89.00 \pm 0.17$ & $97.07 \pm 0.23$ & $91.09 \pm 0.31$ \\
M13 & $92.35 \pm 0.13$ & $89.67 \pm 0.25$ & $96.08 \pm 0.10$ \\
M14 & $98.90 \pm 0.20$ & & 90.25 \\
\hline
\end{tabular}

Table 4: In vitro cumulative percentage drug release of pirenzepine mucoadhesive microspheres formulations M1-M7 and marketed product

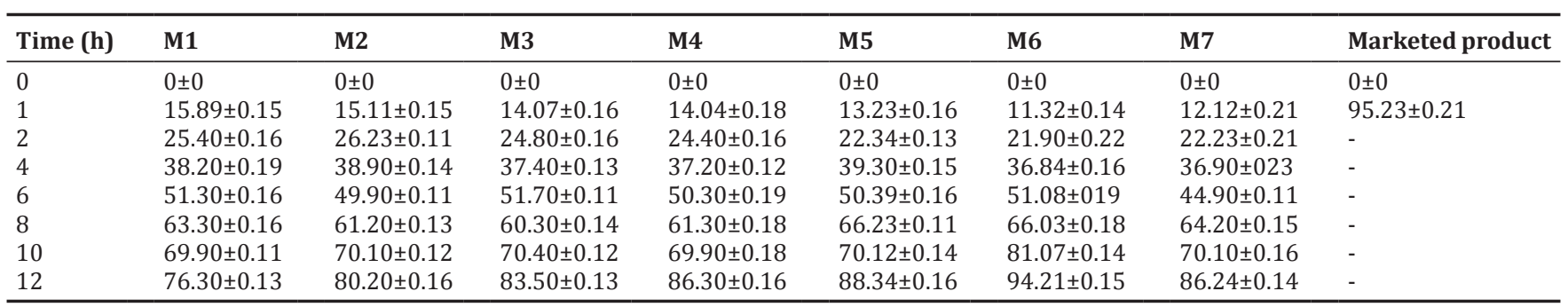




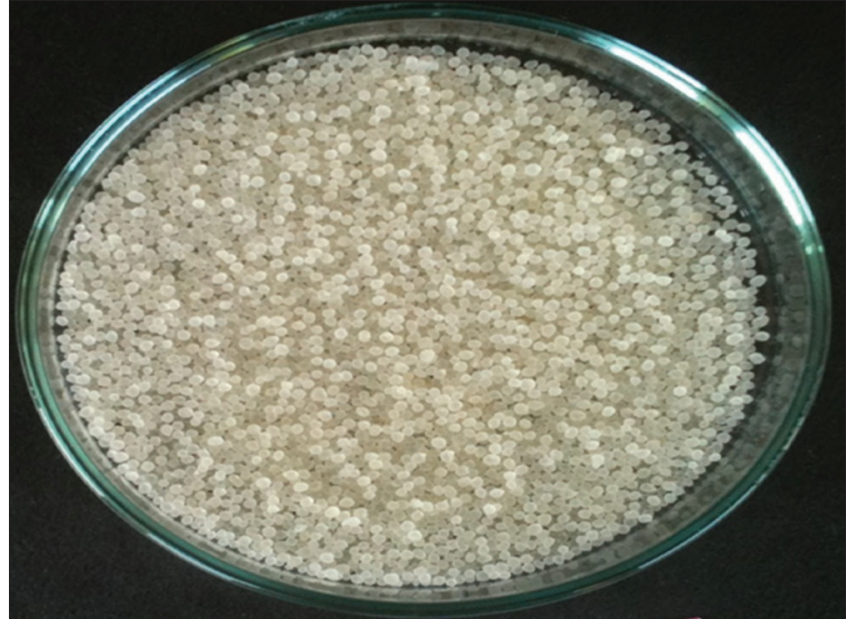

AQ1

Fig. 1: Pirenzepine mucoadhesive microspheres

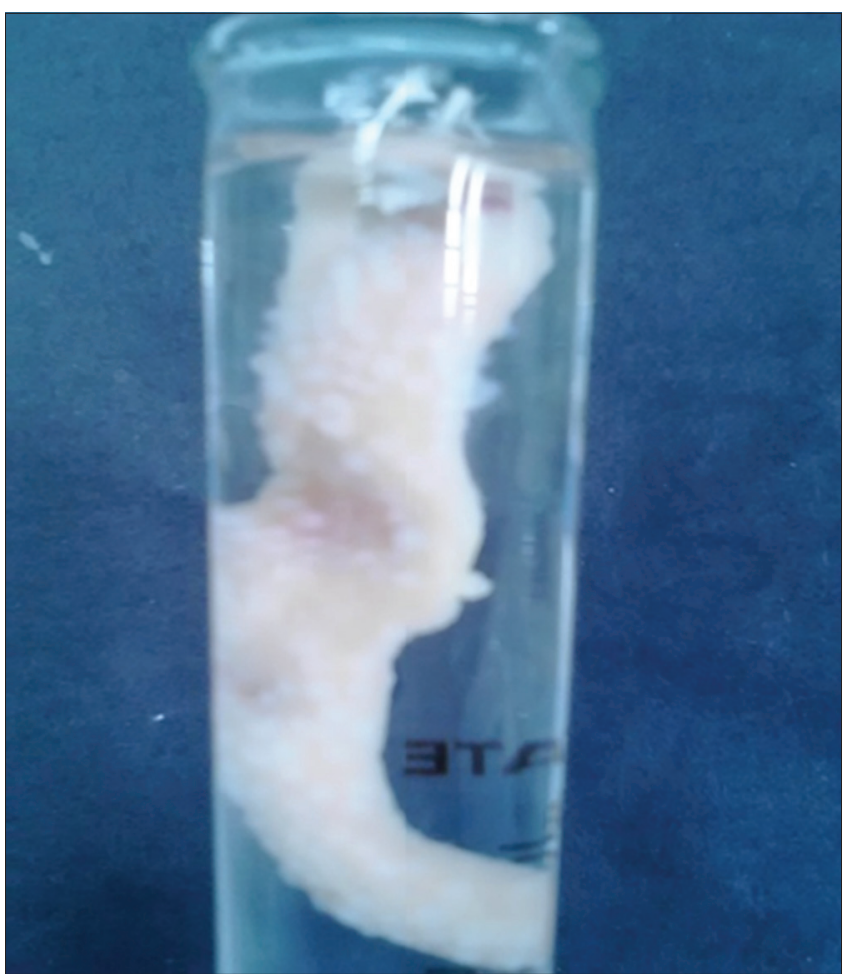

Fig. 2: Pictorial diagram showing mucoadhesive property of mucoadhesive microspheres in Chic Intestine

\section{Stability studies}

Stability testing was carried out at $40^{\circ} \mathrm{C} \pm 2^{\circ} \mathrm{C} / 75 \% \mathrm{RH} \pm 5 \% \mathrm{RH}$ for 6 months using stability chamber (Thermo Lab, Mumbai). Samples were withdrawn at specified intervals $0,30,60,120$, and 180 days period according to ICH guidelines. Various in vitro parameters such as percentage yield, encapsulation efficiency, and cumulative percentage drug release studies were conducted [20].

\section{In vivo bioavailability studies}

Pharmacokinetic study

The optimized mucoadhesive formulation M13 was used for in vivo studies. The animals used for in vivo experiments were of either sex New Zealand white rabbits weighing, 2-3 kg. The study included 12 animals, and six rabbits were kept in each group. Rabbits were kept on fasting $12 \mathrm{~h}$ before administration of the drug and until $24 \mathrm{~h}$ post dosing. Standard diet and water ad libitum were given for rabbits

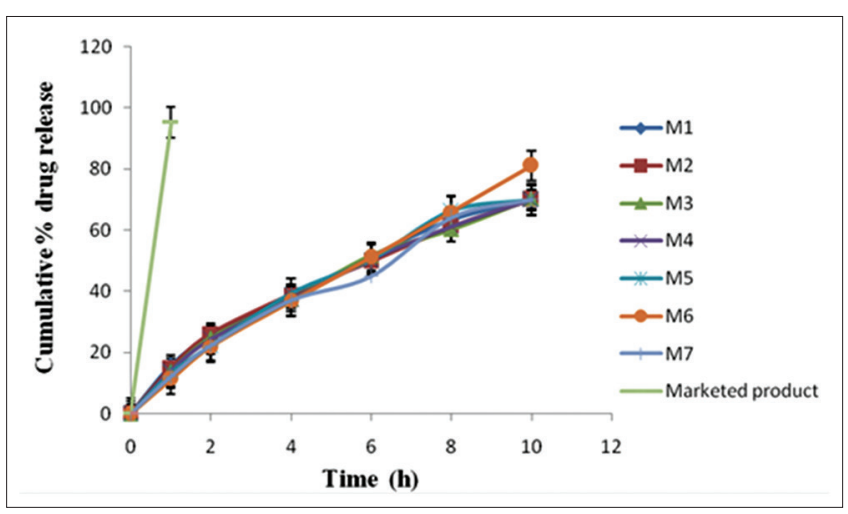

Fig. 3: In vitro cumulative percentage drug release of pirenzepine mucoadhesive microspheres formulations M1-M7 and marketed product

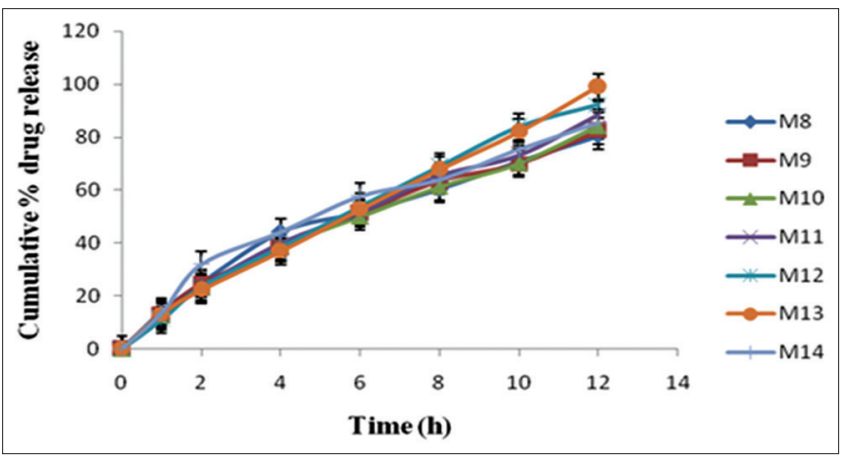

Fig. 4: In vitro cumulative percentage drug release of pirenzepine mucoadhesive microspheres M8-M14

throughout the study. The protocol of animal study was approved by the Institutional Animal Ethics Committee with no: P31/VCP/ IAEC/2015/9/DBP/AE15/Rabbits.

The Group A received optimized formulation through oral route administration of drug solution. The Group B received oral administration of marketed formulation (tablet) was suspended in $1.0 \mathrm{ml}$ saline and administered orally using a rubber tube under nonanesthetic condition. Blood samples $(0.5 \mathrm{ml})$ at different time intervals $0,0.5,1,1.5,2,4,6,8,12,16,20$, and $24 \mathrm{~h}$ were withdrawn by marginal ear vein. Heparin was added to collected blood samples to prevent blood clotting. The samples were centrifuged at $5000 \mathrm{rpm}$ for $5 \mathrm{~min}$ at $-20^{\circ} \mathrm{C}$ until analysis. The several pharmacokinetic parameters such as $\mathrm{C}_{\max ,} \mathrm{T}_{\max }, \mathrm{AUC}_{0-\mathrm{t}} \mathrm{AUC}_{0-\alpha,}$ elimination half-life $\left(\mathrm{t}_{1 / 2}\right)$, and elimination rate constant (Kel) were calculated. The kinetic parameters were calculated by compartmental method using WinNonlin $3.3^{\circledR}$ software (Pharsight Mountain View, CA USA). All values are expressed as the mean \pm standard deviation (SD) [21].

\section{Statistical analysis}

All the data were expressed as the mean \pm SD. Statistical analysis was carried out employing ANOVA using the GraphPad Instat software followed by Tukey-Kramer multiple comparison tests. A value of $\mathrm{p}<0.05$ was considered statistically significant [22]

\section{RESULTS AND DISCUSSION}

Mucoadhesive microspores

The results of micromeritic properties studies are given in Table 2. The particle size of M1-M14 varied from $65.29 \pm 0.13 \mu \mathrm{m}$ to $91.45 \pm 0.21 \mu \mathrm{m}$. The bulk density and tapped density of prepared microspheres were found to be $0.58-0.83 \mathrm{~g} / \mathrm{cm}^{3}$ and $0.59-0.91 \mathrm{~g} / \mathrm{cm}^{3}$, respectively. The angle of repose value was found to be $19^{\circ} .54$ to $30^{\circ} .91$, indicating that the prepared microsphere flow properties fall in the category of 


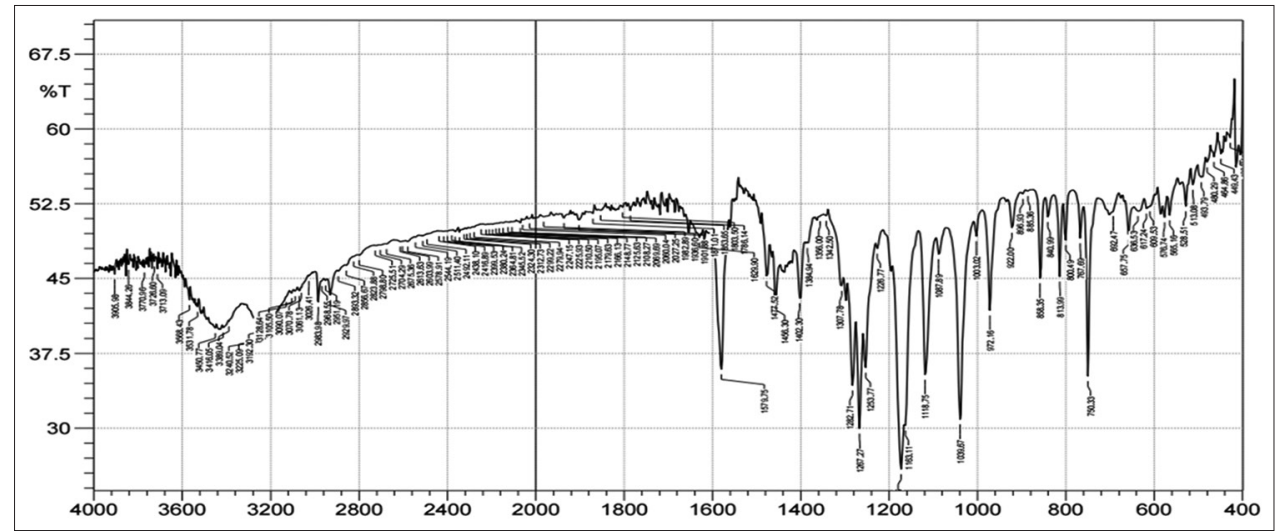

Fig. 5: Fourier transform infrared spectrum of pure drug pirenzepine

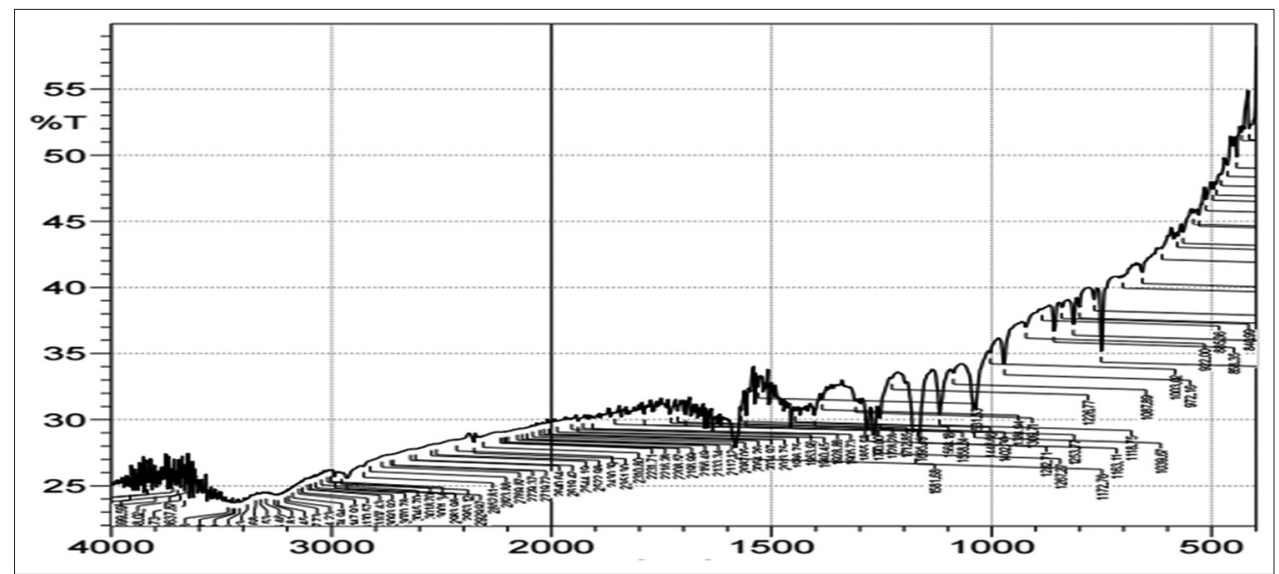

Fig. 6: Fourier transform infrared spectrum of optimized formulation of mucoadhesive microspheres M13

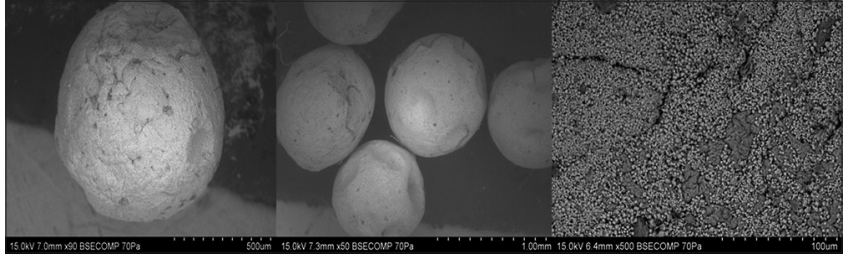

Fig. 7: Scanning electron micrographs of mucoadhesive microspheres at several magnifications

excellent to good flow characteristics. The Carr's index of microsphere formulations was found to be $8.41-14.23 \%$ indicating a excellent to good flowability.

The values of percentage yield (75.45-98.90\%), entrapment efficiency (76.00-97.07\%), swelling index (70.12-96.08\%), and mucoadhesiveness (69.00-95.50\%) of pirenzepine microspheres were mentioned in Table 3. This showed that the hydroxypropyl methylcellulose K15M possesses good swelling capacity and could retard the release of pirenzepine from microsphere. The pictorial diagram of mucoadhesive property of pirenzepine microspheres in Chic Intestine was shown in Fig. 2.

In vitro drug release studies

Drug release profile of pirenzepine microspheres was compared with that of the marketed formulation and results obtained are compared as shown in Table 4 and 5 . The optimized formulation M13 drug release was found $99.07 \pm 0.17 \%$ within $12 \mathrm{~h}$ whereas as marketed formulation showed the $95.23 \pm 0.21 \%$ within $1 \mathrm{~h}$. Therefore, a sustained drug release pattern was observed for optimized formulation (M13).
Mathematical modeling of optimized formula of mucoadhesive microspheres

Drug release kinetic data for pirenzepine mucoadhesive microspheres was shown in Table 6. The optimized formulation M13 followed zeroorder and Korsmeyer-Peppas release kinetics with regression values ranging from 0.951 to 0.994 , respectively. The $n$-value was 0.812 indicating that the pirenzepine release from the microspheres was followed the erosion and diffusion controlled.

\section{CHARACTERIZATION}

FTIR

To develop a stable, optimized mucoadhesive microsphere, the drug-excipient interaction study was performed during the product development stage generally by employing FTIR spectroscopy. The presence of characteristic absorption bands of Pure drug Pirenzepine (Fig. 5) and the optimized formulation (Fig. 6) suggest that there is no interaction takes place between the drug and excipients used in the formulation

\section{SEM studies}

Pirenzepine mucoadhesive microspheres

The scanning electron micrographs of pirenzepine microspheres were shown in Fig. 7. From the SEM studies confirmed that the prepared microspheres were spherical in shape with the smooth and porous surface. The porous surface is mainly responsible for drug release from microspheres.

\section{Stability studies}

Stability studies of the prepared pirenzepine mucoadhesive microspheres were carried out by maintaining the best formulation 
Table 5: In vitro cumulative percentage drug release of pirenzepine mucoadhesive microspheres formulation from M8 to M14

\begin{tabular}{|c|c|c|c|c|c|c|c|}
\hline Time (h) & M8 & M9 & M10 & M11 & M12 & M13 & M14 \\
\hline 0 & $0 \pm 0$ & $0 \pm 0$ & $0 \pm 0$ & $0 \pm 0$ & $0 \pm 0$ & $0 \pm 0$ & $0 \pm 0$ \\
\hline 1 & $14.05 \pm 0.15$ & $13.34 \pm 0.22$ & $12.70 \pm 0.11$ & $12.30 \pm 0.21$ & $11.28 \pm 0.15$ & $13.31 \pm 0.22$ & $13.63 \pm 0.13$ \\
\hline 2 & $24.80 \pm 0.16$ & $24.40 \pm 0.12$ & $23.11 \pm 0.13$ & $23.40 \pm 0.11$ & $23.50 \pm 0.16$ & $22.33 \pm 0.15$ & $32.01 \pm 0.12$ \\
\hline 4 & $44.40 \pm 0.19$ & $38.20 \pm 0.11$ & $38.63 \pm 0.16$ & $39.92 \pm 0.15$ & $38.60 \pm 0.13$ & $37.00 \pm 0.18$ & $44.20 \pm 0.16$ \\
\hline 6 & $51.70 \pm 0.16$ & $51.30 \pm 0.15$ & $49.92 \pm 0.18$ & $51.40 \pm 0.13$ & $53.80 \pm 0.16$ & $52.84 \pm 0.16$ & $57.86 \pm 0.12$ \\
\hline 8 & $60.30 \pm 0.15$ & $63.30 \pm 0.16$ & $61.20 \pm 0.16$ & $65.20 \pm 0.11$ & $68.90 \pm 0.18$ & $67.84 \pm 0.14$ & $64.03 \pm 0.14$ \\
\hline 10 & $70.70 \pm 0.11$ & $69.91 \pm 0.21$ & $70.13 \pm 0.15$ & $73.12 \pm 0.16$ & $83.90 \pm 0.12$ & $82.00 \pm 0.11$ & $75.29 \pm 0.11$ \\
\hline
\end{tabular}

Table 6: Stability studies of optimized mucoadhesive microspheres

\begin{tabular}{llll}
\hline Retest time for optimized formulation & Percentage yield & Entrapment efficiency (\%) & In vitro drug release profile (\%) \\
\hline 0 days & $98.90 \pm 0.20$ & $97.07 \pm 0.23$ & $99.07 \pm 0.17$ \\
30 days & $97.40 \pm 0.02$ & $96.4 \pm 0.16$ & $97.20 \pm 0.04$ \\
60 days & $95.22 \pm 0.05$ & $94.53 \pm 0.15$ & $95.33 \pm 0.12$ \\
1 d days & $94.13 \pm 0.01$ & $93.55 \pm 0.20$ & $94.68 \pm 0.25$ \\
180 days & $93.11 \pm 0.23$ & $92.34 \pm 0.07$ & $93.45 \pm 0.19$ \\
\hline
\end{tabular}

Table 7: Comparison of pharmacokinetic parameters of pirenzepine optimized formulation and marketed product

\begin{tabular}{lll}
\hline Parameters & Pirenzepine optimized formulation & Marketed product \\
\hline $\mathrm{C}_{\max }(\mathrm{ng} / \mathrm{ml})$ & $2.15 \pm 0.01$ & $2.85 \pm 0.01$ \\
$\mathrm{AUC}_{0-\mathrm{t}}(\mathrm{ng} \cdot \mathrm{h} / \mathrm{ml})$ & $11.15 \pm 1.12$ & $7.21 \pm 1.26$ \\
$\mathrm{AUC}_{0-\infty}(\mathrm{ng} \cdot \mathrm{h} / \mathrm{ml})$ & $14.42 \pm 1.16$ & $10.15 \pm 1.13$ \\
$\mathrm{~T}_{\max }(\mathrm{h})$ & $3.00 \pm 0.05$ & $1.00 \pm 0.04$ \\
$\mathrm{t}_{1 / 2}(\mathrm{~h})$ & $5.85 \pm 0.41$ & $3.91 \pm 0.01$ \\
Kel $\left(\mathrm{h}^{-1}\right)$ & $1.93 \pm 0.11$ & $1.15 \pm 0.33$ \\
\hline
\end{tabular}

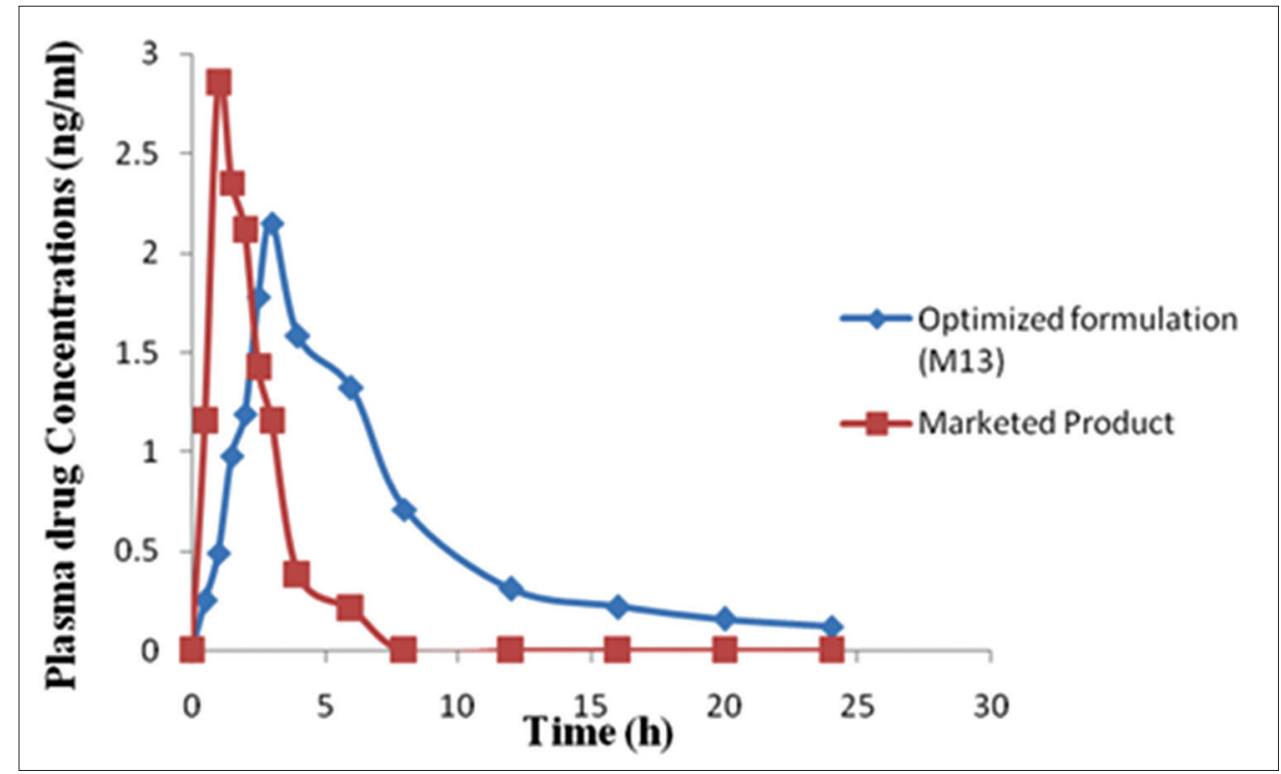

Fig. 8: Plasma concentrations at different time intervals for pirenzepine optimized formulation (M13) and marketed product

M13 at $40 \pm 20^{\circ} \mathrm{C} / 75 \pm 5 \%$ RH for 6 months. For optimized formulation, M13 confirmed the negligible change in percentage yield, percentage drug release, and encapsulation efficiency as mentioned in Table 7.

\section{In vivo studies}

Pharmacokinetic study

In the present research study, various kinetic parameters of optimized formulation include $\mathrm{C}_{\max }, \mathrm{t}_{\max }, \mathrm{AUC}_{0-\mathrm{t}}, \mathrm{AUC}_{0-\alpha^{\prime}}$, elimination half-life $\left(\mathrm{t}_{1 / 2}\right)$, and elimination rate constant were calculated and compared with a marketed product, showed in Table 8 . The $\mathrm{C}_{\text {max }}$ of marketed product $(2.85 \pm 0.01 \mathrm{ng} / \mathrm{ml})$ was found higher than optimized formulation
$(2.15 \pm 0.01 \mathrm{ng} / \mathrm{ml})$ due to fast initial drug release; it leads to nonequivalence of the dosage forms. The initial phase drug release rate should be controlled and optimized by the addition of sodium alginate and chitosan so as to reach the target range.

The significant difference in $\mathrm{T}_{\text {max }}, \mathrm{AUC}_{0-\mathrm{t}}, \mathrm{AUC}_{0-\alpha^{\prime}}$, and Kel values of optimized formulation and marketed product were observed this could be due to slow release and prolonged drug absorption from the optimized formulation. Low oral bioavailability (25\%) of pirenzepine from the marketed product was due to its narrow absorption window in the upper part of GIT. However, in the optimized formulation, gastric 
residence time was increased hence reducing the dosing frequency and sustain the drug release in absorbable regions of the GIT thereby increasing its bioavailability. This observation was supported by ANOVA results $(\mathrm{p}<0.05)$. The optimized microsphere formulation was 1.5 -fold higher bioavailability than the marketed product.

The optimized pirenzepine microsphere formulation (M13) and marketed product mean plasma concentration profile results were shown in Fig. 8. The optimized formulation sustains the effect for $24 \mathrm{~h}$ when compared with a marketed product for $6 \mathrm{~h}$. This shows the optimized mucoadhesive microspheres formulation had prolonged gastric residence time and absorption than that of the marketed product.

\section{CONCLUSION}

In the present research study, stable gastroretentive mucoadhesive dosage form was fruitfully prepared by ionotropic gelation method containing pirenzepine. The technique used was found to be handling easy, inexpensive, and reproducible process. The results of the study revealed that the sodium alginate, chitosan, and calcium chloride considerably affected the drug incorporation efficiency, particle size, percentage yield, and percentage mucoadhesion. The optimized formulation (M13) was found to be efficient with a particle size $(89.04 \pm 0.21 \mu \mathrm{m})$, percentage yield (98.90\%), encapsulation efficiency (97.07\%), swelling index (96.08\%), and mucoadhesion (95.50\%). The mucoadhesive property facilitates the microspheres to adhere to the gastric mucosal surface and reside in stomach for prolonged time which eventually leads to better bioavailability. Cumulative percentage drug release studies showed sustained drug release up to $99.07 \pm 0.17 \%$ (12 h). Drug release from pirenzepine microspheres followed zero-order and Korsmeyer-Peppas model suggested that it followed the erosion and diffusion-controlled mechanism. The FTIR studies displayed that drug and excipients were compatible. SEM results revealed that the prepared microspheres were spherical in shape. The stability of optimized formulation (M13) was studied as per the ICH guidelines and found stable for 6 months. The pharmacokinetic study in New Zealand white rabbits revealed the oral bioavailability of pirenzepine in microspheres was enhanced due to the prolonged residence time in GIT in comparison with a marketed product. The optimized formulation was shown much higher bioavailability than the marketed product. Microspheres would be a promising DDS could play a potentially significant role in pharmaceutical drug delivery for gastric therapeutics.

\section{AUTHOR'S CONTRIBUTION}

All the authors have contributed equally.

\section{CONFLICTS OF INTEREST}

No conflicts of interest were raised by the authors.

\section{REFERENCES}

1. Tao Y, Lu Y. Development of mucoadhesive microspheres of acyclovir with enhanced bioavailability. Int J Pharm 2009;378:30-6.

2. Jelvehgari M, Barar J. Effects of process variables on micromeritic properties and drug release of non-degradable microparticles. Adv Pharm Bull 2011;1:18-26.

3. Velmurugana S, Ali MA. Preparation and evaluation of maraviroc mucoadhesive microspheres for gastro retentive drug delivery. Int $\mathrm{J}$ Pharm Pharm Sci 2015; 7:208-14

4. Jagtap YM, Bhujbal RK. Effect of various polymers concentrations on physicochemical properties of floating microspheres. Indian J Pharm Sci 2010;74:512-20.

5. Sriram N, Katakam P. Formulation and evaluation of mucoadhesive microspheres of pioglitazone hydrochloride prepared by ionotropic external gelation technique. J Encap Ads Sci 2016;6:22-34.

6. Araratha D, Velmurugana S. Formulation and evaluation of nevirapine mucoadhesive microspheres. Int J Pharm Pharm Sci 2015;7:342-8.

7. Li Y, He H. Preparation, stability and pharmacokinetics evaluation of lipid microspheres loading a promising antitumor candidate, Timataxel. Asian J pharm Sci 2016;11:771-9.

8. Vergin H, Mascher H. Pharmacokinetics and bioequivalence of different formulations of pirenzepine. Arzneimittelforsc Hung 1986;36:1409-12.

9. Kaur R, Gulati M. Role of synbiotics in polysaccharide assisted colon targeted microspheres of Mesalamine for the treatment of ulcerative colitis. Int J Biol Macromol 2016;95:438-50.

10. Wang QS, Wang GF. Colon targeted oral drug delivery system based on chitosan/alginate microspheres loaded with icariin in the treatment of ulcerative colitis. Int J Pharm 2016;515:176-85.

11. Piacentini E, Yan M. Development of enzyme-loaded PVA microspheres by Membrane Emulsification. J Membrane Sci 2016;524:79-86.

12. Małgorzata W, Marcin Z. Tasting cetirizine-based microspheres with an electronic tongue. Sen Actu B Chem 2016;238:1190-8.

13. Maarten J, Nina W. Celecoxib-loaded PEA microspheres as an auto regulatory drug-delivery system after intra-articular injection. J Control Rele 2016;244:30-40.

14. Velmurugan S, Ali MA. Formulation and evaluation of maraviroc mucoadhesive microsheres by ionotropic gelation method. Int J Pharm Sci 2015;5:294-302.

15. Xuehua Z, Xiaole Q. Preparation of multiple-unit floating-bioadhesive cooperative mini tablets for improving the oral bioavailability of famotidine in rats. Drug Deliv 2013;21:1-8

16. Malladi M, Jukanti R. Formulation development and evaluation of a novel bi-dependent clarithromycin gastroretentive drug delivery system using box-behnken design. J Drug Deli Sci Tech 2016;35:134-45.

17. Hooda A, Nanda A. Optimization and evaluation of gastroretentive ranitidine $\mathrm{HCl}$ microspheres by using design expert software. Int J Biol Macromol 2012;51:691-700.

18. Abhijeet $\mathrm{D}$, Deepak B. In vitro, ex vivo and in vivo performance of chitosan-based spray-dried nasal mucoadhesive microspheres of diltiazem hydrochloride. J Drug Deli Sci Technol 2016;31:108-17.

19. Antonio JR, Ronald JN. Microencapsulation of lipophilic drugs in chitosan-coated alginate microspheres. Int J Pharm 1999;187:115-23.

20. Tyagi L, Kori M. Stability study and in-vivo evaluation of lornoxicam loaded ethyl cellulose microspheres. Int J Pharm Sci Drug Res 2014;6:26-30.

21. Sunil K, Govind P. A novel calcium silicate-based microspheres of repaglinide: In vivo investigations. J Control Release 2006;113:111-6.

22. Phutane $\mathrm{P}$, Shidhaye $\mathrm{S}$. In vitro evaluation of novel sustained release microspheres of glipizide prepared by the emulsion solvent diffusionevaporation method. J Young Pharm 2010;2:35-41. 